\title{
Ménétrier disease with antrum polyposis and gastritis cystica profunda
}

A 46-year-old man was admitted with epigastric pain, weight loss, and hypoalbuminemia. He had no history of gastric surgery. A gastroscopy revealed giant polypoid gastric folds within the gastric body and fundus ( Fig.1) and several polyps with central erosion in the gastric antrum ( Fig.2). Biopsies of the gastric body and antral lesions revealed chronic gastritis. Endoscopic ultrasound showed a thickened mucosal layer, with multiple anechogenic areas, indicative of cysts, in the mucosal and submucosal layers ( Fig.3). Snare biopsy of gastric corpus and antral lesions showed elongated foveolar epithelium with foveolar mucous cell hyperplasia and cystic dilation of the foveolar glands in the basal portion of mucosa, extending to the submucosa ( Fig.4). No dysplasia was observed, and tests for cytomegalovirus and Helicobacter pylori were negative. These findings were consistent with Ménétrier disease (MD) with coexisting gastritis cystica profunda (GCP). After discussing the cancer risk and treatment options with the patient, we initiated treatment with a proton pump inhibitor (PPI).

MD is an uncommon, idiopathic, hyperplastic gastropathy characterized by hyperplasia of foveolar mucous cells resulting in thickened gastric folds and hypoalbuminemia [1]. It mostly involves the gastric fundus and body [1]. GCP is characterized by a diffuse submucosal proliferation of cystic glands that mostly develops in patients who have undergone gastroenterostomy [2]. To our knowledge this is only the second report of MD associated with antral polyposis and GCP [3]. There are many reports indicating that MD and GCP are potentially precancerous lesions $[1,4]$, and thus coexisting GCP may increase the cancer risk associated with MD. The best treatment for MD, especially in association with GCP, is still unclear. The therapeutic options include testing for and treatment of cytomegalovirus and H. pylori infection, antisecretory treatment with a PPI or histamine-2 receptor antagonist, octreotide, monoclonal antibodies to epidermal growth factor receptor, and gastrectomy [1].

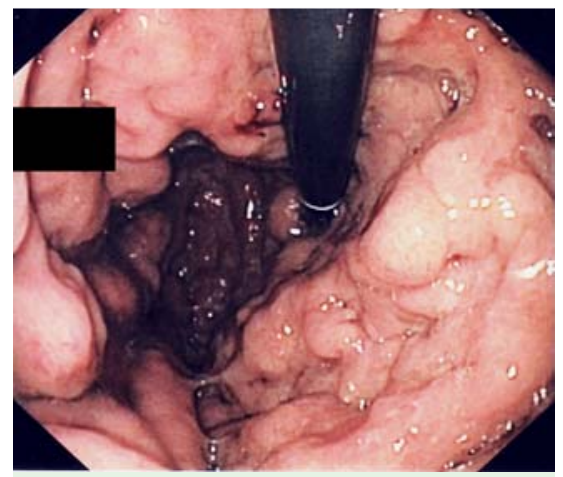

Fig. 1 Gastroscopic view of the gastric body and fundus in a 46-year-old man with epigastric pain, weight loss, and hypoalbuminemia showing giant gastric folds with a polypoid appearance.

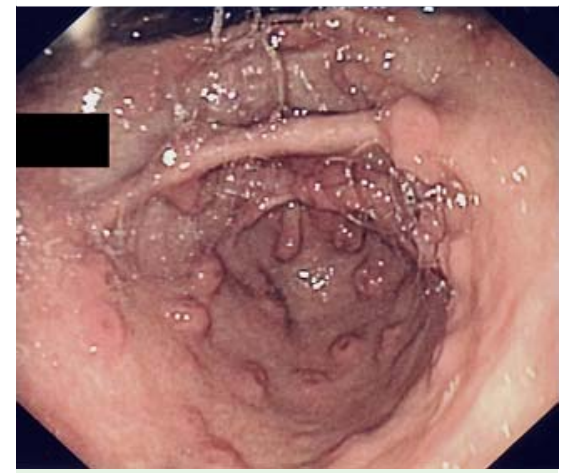

Fig.2 Gastroscopic view of the gastric antrum showing several polyps with central erosion.

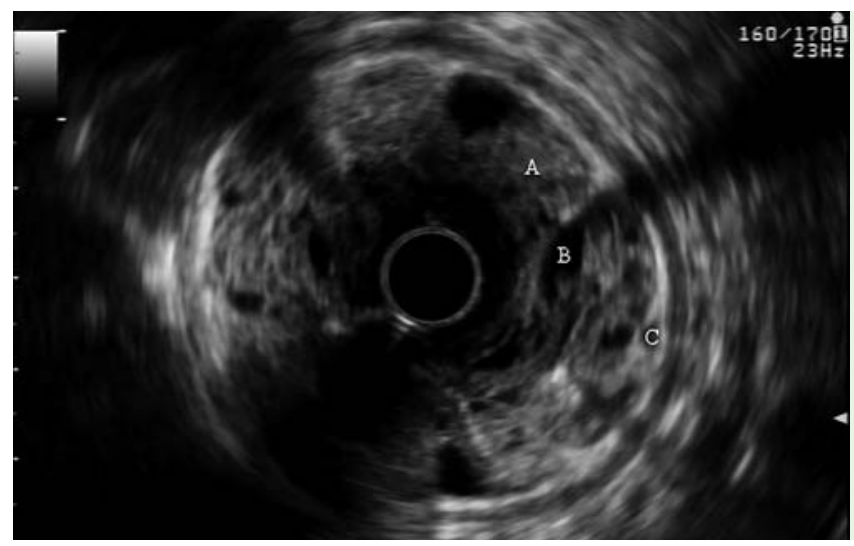

Fig. 3 Endoscopic ultrasound view showing a thickened mucosal layer (A), with multiple anechogenic areas, indicating the presence of cysts, in the mucosal (B) and submucosal (C) layers.

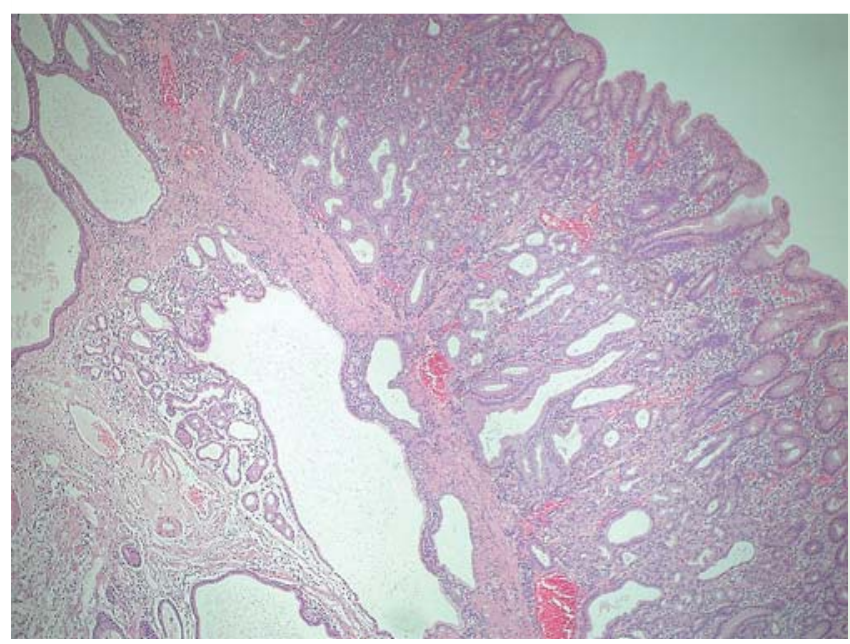

Fig.4 Histologic section of the snare biopsy specimen showing elongated foveolar epithelium with foveolar mucous cell hyperplasia and cystic dilation of the foveolar glands in the basal portion of mucosa, extending to the submucosa. 
Endoscopy_UCTN_Code_CCL_1AB_2AD_3AD

Competing interests: None

\section{J. B. Soares, P. Bastos, R. Gonçalves}

Department of Gastroenterology, Braga Hospital, Braga, Portugal

\section{References}

1 Toubia N, Schubert ML. Menetrier's disease. Curr Treat Options Gastroenterol 2008; 11: 103-108

2 Bechade D, Desrame J, Algayres JP. Gastritis cystica profunda in a patient with no history of gastric surgery. Endoscopy 2007; 39: 01E80-81

3 Lim JK, Jang YJ, Jung MK et al. Menetrier disease manifested by polyposis in the gastric antrum and coexisting with gastritis cystica profunda. Gastrointest Endosc 2010; 72 : $1098-1100$

4 Roepke TK, Purtell K, King EC et al. Targeted deletion of Kcne2 causes gastritis cystica profunda and gastric neoplasia. PLoS One 2010; 5: e11451

\section{Bibliography}

Dol http://dx.doi.org/

10.1055/s-0031-1291561

Endoscopy 2012; 44: E56-E57

(c) Georg Thieme Verlag KG

Stuttgart · New York

ISSN 0013-726X

\section{Corresponding author}

\section{J. B. Soares}

Gastroenterology Department of Braga Hospital Sete Fontes

S. Victor

4701-243 Braga

jbrunosoares@yahoo.com 